\title{
Evaluation of FAOAqua Crop model for wheat under different irrigation regimes
}

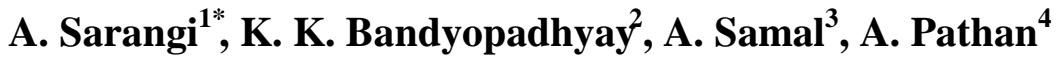 \\ ${ }^{1,3,4}$ Water Technology Centre, ICAR-IARI, New Delhi-12, India \\ ${ }^{2}$ Division of Agricultural Physics, ICAR-IARI, New Delhi - 12, India \\ *Corresponding author. E-mail: asarangi@iari.res.in
}

Received: July 30, 2015: Revised received: December 27 2015; Accepted: March 22, 2016

\begin{abstract}
The experiment was conducted at the research farm of the Water Technology Centre, IARI, New Delhi during rabi seasons of 2010-11and 2011-12. Irrigation treatments include irrigation applied at 50\% deficit $\left(\mathrm{W}_{1}\right)$ and $25 \%$ deficit $\left(\mathrm{W}_{2}\right)$ and full irrigation $\left(\mathrm{W}_{3}\right)$ under recommended fertilization levels with split doses of $\mathrm{N}$-fertilizer. Full irrigation treatment was based on irrigations to meet the soil moisture deficit up to the field capacity (FC) level and deficit irrigation treatments of $25 \%$ and $50 \%$ were imposed with respect to the full irrigation. The model was calibrated with experiment generated data sets of rabi 2010-11 and validated using the data set of rabi 2011-12. It was observed that the validated model performed well for grain yield prediction with absolute prediction error of $2.9 \%$, $0.91 \%$ and $7.85 \%$ for full, $25 \%$ deficit and $50 \%$ deficit irrigation levels, respectively. Also, for prediction of biomass yield the prediction error ranged from $11.81 \%$ to $28.96 \%$ for all three irrigation treatments. Moreover, the validated model was observed to predict the water productivity with absolute prediction errors of $43.57 \%, 13.87 \%$ and $12.8 \%$ for full, $25 \%$ deficit and $50 \%$ deficit irrigation treatment levels, respectively. Nonetheless, it was observed from this study that the AquaCrop model can be used to simulate the grain and biomass yield for wheat crop with acceptable accuracy under different irrigation regimes in a semi-arid enviroment.
\end{abstract}

Keywords: AquaCrop model, Calibration, Irrigation regimes, Validation, Wheat crop

\section{INTRODUCTION}

Crop growth simulation models of varying complexity have been developed for predicting the effects of soil, water and nutrients on grain and biomass yields and water productivity of different crops. AquaCrop, a crop water productivity model developed by the Land and Water Division of FAO and released for use during 2009 (Steduto et al., 2009), was used to simulate yield response to water of several herbaceous crops. The AquaCrop model has been parameterized and validated for simulating yield, biomass and water productivity of different crops. Mkhabela and Bullock (2012) evaluated AquaCrop for wheat crop grown at five different experimental sites in Canadian Prairies. They reported that the difference between observed and simulated grain yield was only $3 \%$ and the difference between observed and simulated total soil water content was $2 \%$. They concluded that the AquaCrop can be a valuable tool for simulating both wheat grain yield and soil water content on the Canadian Prairies, particularly considering the fact that the model requires a relatively small number of explicit and mostly intuitive input data, which can be readily available or easily collected. Salemi et al. (2011) used the AquaCrop model for simulating the grain yield and water productivity of winter wheat grown in the Gavk- huni River Basin (GRB), central Iran under deficit irrigation condition. It was observed that the water productivity for wheat was in the range of 0.91 to 1.49 $\mathrm{kg} \mathrm{m}^{-3}$ and its maximum value was for the crop grown under $40 \%$ deficit irrigation treatment. Andarzian et al. (2011) evaluated AquaCrop model for its ability to simulate wheat yield under full and deficit water conditions in a hot dry environment in south of Iran. The AquaCrop model was able to accurately simulate soil moisture content of root zone, crop biomass and grain yield, with normalized root mean square error (RMSE) less than 10\%. Xiangxiang et al. (2013) evaluated AquaCrop model for simulating the impact of irrigation regimes on the biomass and grain yield of wheat. The model was calibrated and validated using the experimental data of wheat grown during the period from 2006 to 2011 in the Changwu Agri-ecological station at Loess Plateau of Shaanxi Province, China. The model simulated results for soil moisture in the root zone depths were in line with the observed values with $\mathrm{R}^{2}$ varying from 0.88 to 0.95 for different irrigation treatments. Moreover, the comparison of model simulated and observed grain yield under the single irrigation, double irrigation, triple irrigation and quadruple irrigation treatments resulted in $\mathrm{R}^{2}$ of $0.80,0.98,0.99$, and 0.77 , respectively. Abedinpour et al. (2012) evaluated AquaCrop for simulating the grain yield and water 
productivity of Kharif Maize in a semi-arid environment of Northern India. It was observed that the prediction error in simulation of grain and biomass yield under all irrigation and nitrogen levels ranged from a minimum of $0.47 \%$ to $5.91 \%$ and maximum of $4.36 \%$ to $11.05 \%$, respectively. The model prediction error in simulating the water productivity (WP) varied from $2.35 \%$ to $27.5 \%$ for different irrigation and nitrogen levels. Over all, the FAO AquaCrop model predicted maize yield with acceptable accuracy under variable irrigation and nitrogen levels. Singh et al. (2013) calibrated and validated FAO AquaCrop model for 10 wheat cultivars experimented in West Bengal and reported that the model performed well with minimal input data in prediction of wheat yield. Iqbal et al. (2014) simulated the soil moisture, grain and biomass yield of winter wheat in the Northern China Plain region and concluded that the model can be used with reliable degree of accuracy. Kumar et al. (2015) compared AquaCrop and SWAP model for prediction of grain yield of salt-tolerant and salt non-tolerant wheat cultivars in the semi-arid region of India and suggested use of AquaCrop model which requires less input data as compared to SWAP, but could predict the crop growth and yield parameters at par with SWAP model. Keeping this in view, a study was undertaken to evaluate the water driven crop growth model AquaCrop (Ver. 4.0 released in June 2012) for predicting the grain and biomass yield of rabi (winter) wheat using the experimental data of WTC farm, IARI, New Delhi, India.

\section{MATERIALS AND METHODS}

Site description: The experiment was undertaken in the experimental farm of Water Technology centre (WTC), IARI for wheat experiment of rabi 2010-11 and 2011-12. The field is located at $77^{\circ}$ 9' 36.5 "E longitude and $28^{\circ} 37^{\prime} 55.2^{\prime \prime} \mathrm{N}$ latitude having an average elevation of $230 \mathrm{~m}$ above mean sea level (amsl). Surface irrigation facility with ground water is available in the farm, which provides assured irrigation during the crop growth period. Water available for irrigation in the farm was of salinity less than $1 \mathrm{dSm}^{-1}$, hence the salinity stress was also not considered in the AquaCrop model to simulate the growth and yield of wheat. Climate data during the experiment period for calibration and validation of AquaCrop model was acquired from the automatic weather station located within the IARI farm. The rainfall, maximum and minimum temperature and relative humidity variations as observed during the experiment period for 2010-11and 2011-12 is shown in Table 1 . The daily rainfall and maximum and minimum temperature during crop growth for the year 2010-11 and 2011-12 have been depicted in Figs. 2 and 3 , respectively.

Field layout and experiment details: The data on growth and yield parameters of wheat crop, soil and irrigation scheduling, soil moisture and other input parameters required for model calibration and validation were obtained from the field experiments conducted in the research farm of Water Technology Centre (WTC), IARI, New Delhi, India during the rabi (post-monsoon winter) seasons during years20102011 and 2011-2012.The design of experiment with different irrigation and $\mathrm{N}$-fertilization treatment is shown in Fig. 1. The field experiment was laid in randomized block design comprised of three regimes of irrigation i.e. $\mathrm{W}_{1}: 50 \%$ deficit irrigation (DI), $\mathrm{W}_{2}: 25 \%$ DI and $\mathrm{W}_{3}$ :full irrigation pertaining to crop water requirement and four nitrogen fertilizer treatments including the recommended application of $50 \%$ basal and $50 \%$ at crown root initiation (CRI) stage and split$\mathrm{N}$ doses as basal, at CRI and at heading stage amounting to the total recommended dose of $120 \mathrm{~kg} \mathrm{ha}^{-1}$ of nitrogenous fertilizer. Moreover, the experimental data pertaining to the recommended $\mathrm{N}$-fertilization was used for calibration and validation of AquaCrop model due to limitation of AquaCrop model in handling the split-N fertilization at different growth stages of crop. Wheat cultivar HD2894 was sown with row spacing of $20 \mathrm{~cm}$ in the plot of $6 \times 3.5 \mathrm{~m}$ size. Plot to plot spacing was maintained at $2 \mathrm{~m}$ and replications were separated by $2.75 \mathrm{~m}$ in the entire experiment (Fig.1). The physical and chemical properties of soil of the experiment are presented in table 2 .

Moreover, due to non-availability of any module in AquaCrop to simulate different split $\mathrm{N}$-fertilization treatments imposed at different growth stages, the recommended fertilization level without any fertility stress was simulated in this study. Reference evapotranspiration (ETo) was estimated using modified Penman-Monteith formulae and used in AquaCrop as one of the input climatic parameter. The data on initial condition, soil, climate and crop growth obtained from field were used in AquaCrop model to generate crop yield, biomass and water productivity (WP).Two deficit levels of irrigation water i.e. $50 \%$ $\mathrm{DI}\left(\mathrm{W}_{1}\right), 25 \% \mathrm{DI}\left(\mathrm{W}_{2}\right)$ and full irrigation $\left(\mathrm{W}_{3}\right)$ pertaining to crop water requirement based on soil moisture deficit criterion was taken.

Measured quantity of irrigation water based on soil moisture content was directly applied to the furrows using HDPE pipes to eliminate conveyance loss of water. The harvesting was done during the maturity stage with grain moisture content of about 13$15 \%$.Crop growth parameters viz. above ground biomass, leaf area index and plant height were measured at different growth stages under different irrigation treatments.

Irrigation scheduling in the experiment: All experimental plots were irrigated using surface method of irrigation. Irrigation water depths indicated by the soil moisture deficit (SMD) in each treatment was calculated using soil moisture content before irrigation, root zone depth of plant and bulk density of soil using the Equation 1 
Split plot design

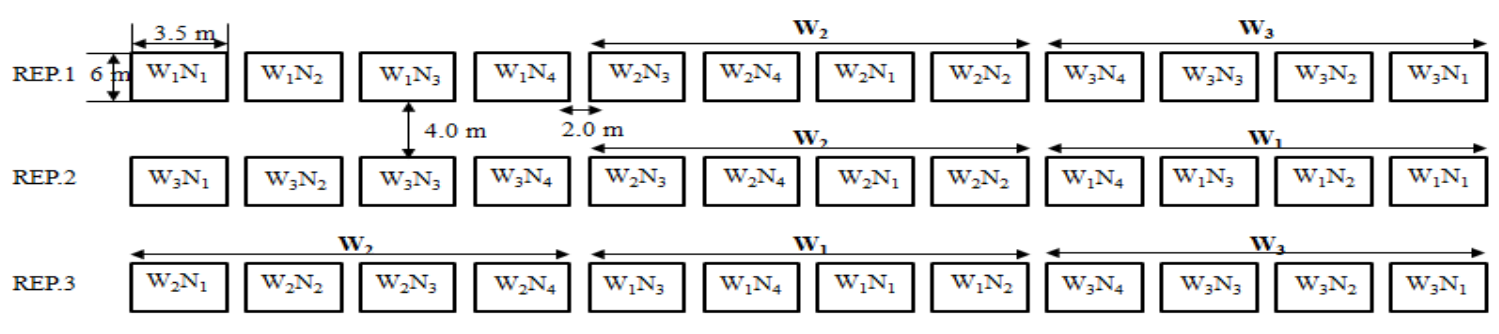

$$
\begin{aligned}
& \text { Irrigation Treatment (W) } \\
& \mathrm{w}_{1}-50 \% \mathrm{DI} \\
& \mathrm{w}_{2}-25 \% \mathrm{DI} \\
& \mathrm{w}_{3}-\text { Full irrigation }
\end{aligned}
$$

Nitrogen Treatment (N)
$\mathrm{N}_{1}-50 \%$ Basal, $50 \%$ CRI
$\mathrm{N}_{2}-50 \%$ Basal, $25 \%$ CRI, $25 \%$ Tillering
$\mathrm{N}_{3}-25 \%$ Basal, $50 \%$ CRI, $25 \%$ Tillering
$\mathrm{N}_{4}-25 \%$ Basal, $25 \%$ CRI, $50 \%$ Tillering

Fig. 1. Layout of the experimental field for rabi2010-11 and 2011-12.

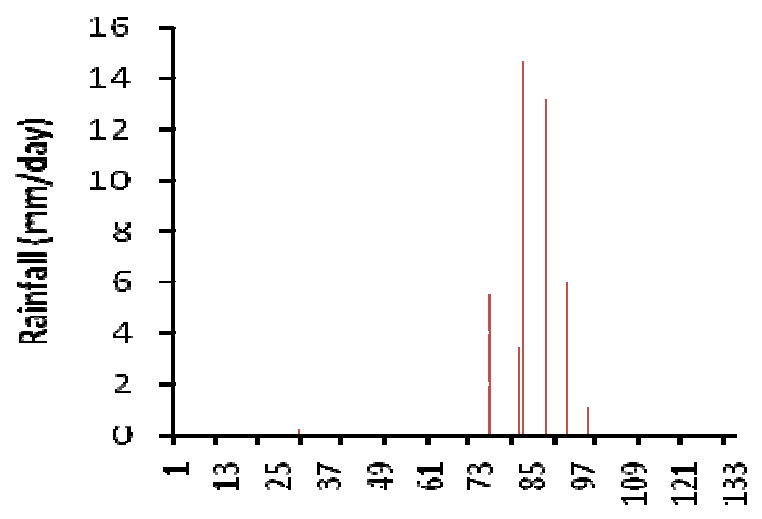

DAS

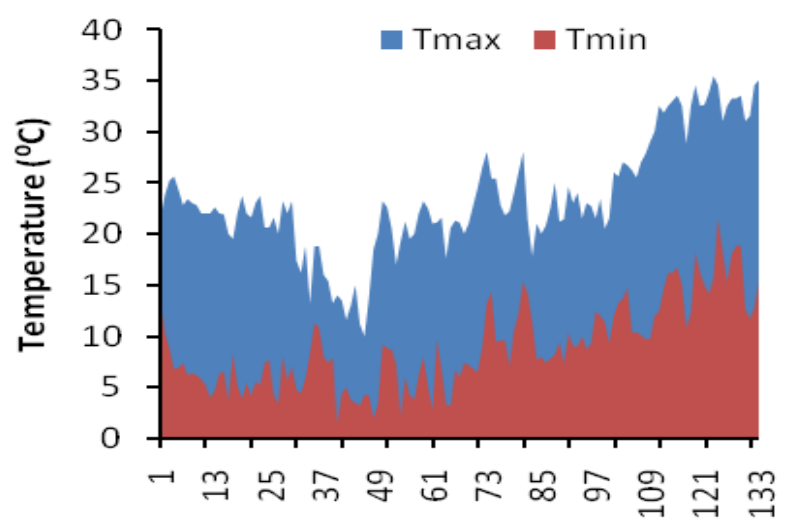

DAS

Fig. 2. Weather parameters during the crop growth period in rabi2010-11.
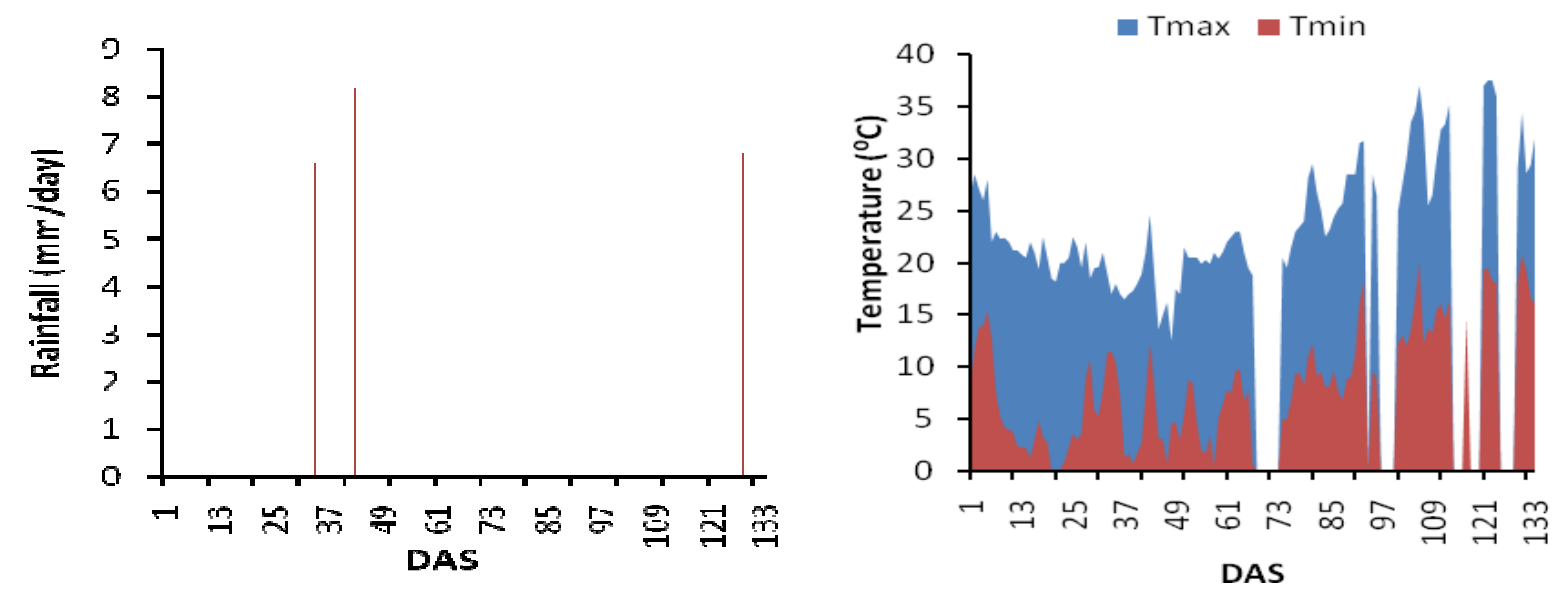

Fig. 3. Weather parameters during the crop growth period in rabi2011-12.

$\mathrm{SMD}=\left(\theta_{\mathrm{Fc}^{-}} \theta_{\mathrm{i}}\right) \times \mathrm{D}_{\mathrm{RZ}} \times \mathrm{B}_{\mathrm{d}} \times \mathrm{f}$

Where,

SMD: soil moisture deficit $(\mathrm{mm}), \theta_{\mathrm{Fc}}$ : soil water content at field capacity $(\%), \theta_{\mathrm{i}}$ : soil water content before irrigation $(\%), \mathrm{D}_{\mathrm{RZ}}$ : root zone depth $(\mathrm{mm}), \mathrm{Bd}$ : bulk density of soil $\left(\mathrm{gcm}^{-3}\right)$ and $\mathrm{f}$ : coefficient of each treatment. The coefficient of each treatment viz. $\mathrm{f}(\mathrm{W} 3)=1$ (full irrigation up to $\mathrm{FC}$ without any deficit), $\mathrm{f}(\mathrm{W} 2)=$ $0.75(25 \% \mathrm{DI}), \mathrm{f}(\mathrm{W} 3)=0.50(50 \% \mathrm{DI})$ were used for different treatments to estimate the quantity of irriga- 

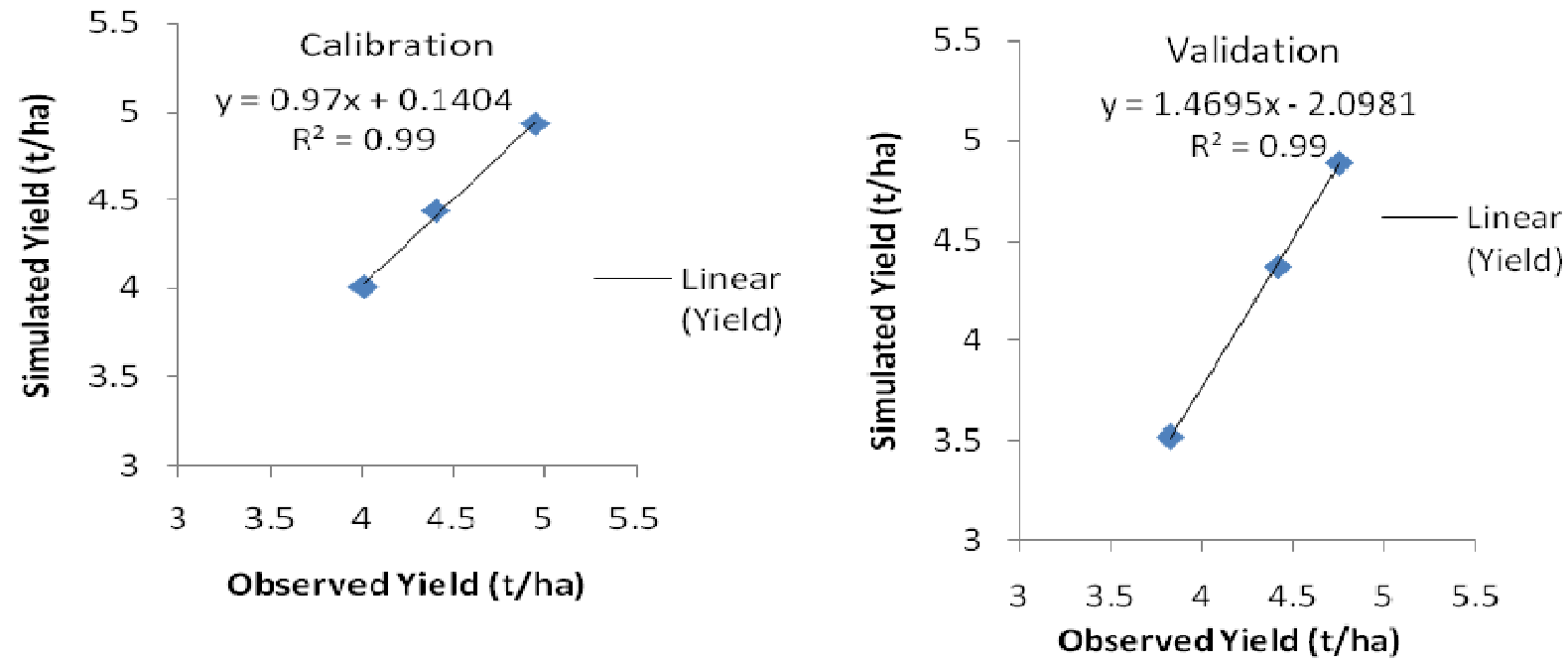

Fig. 4. Model calibration and validation results for grain yield under three different irrigation regimes during rabi 2010-11.
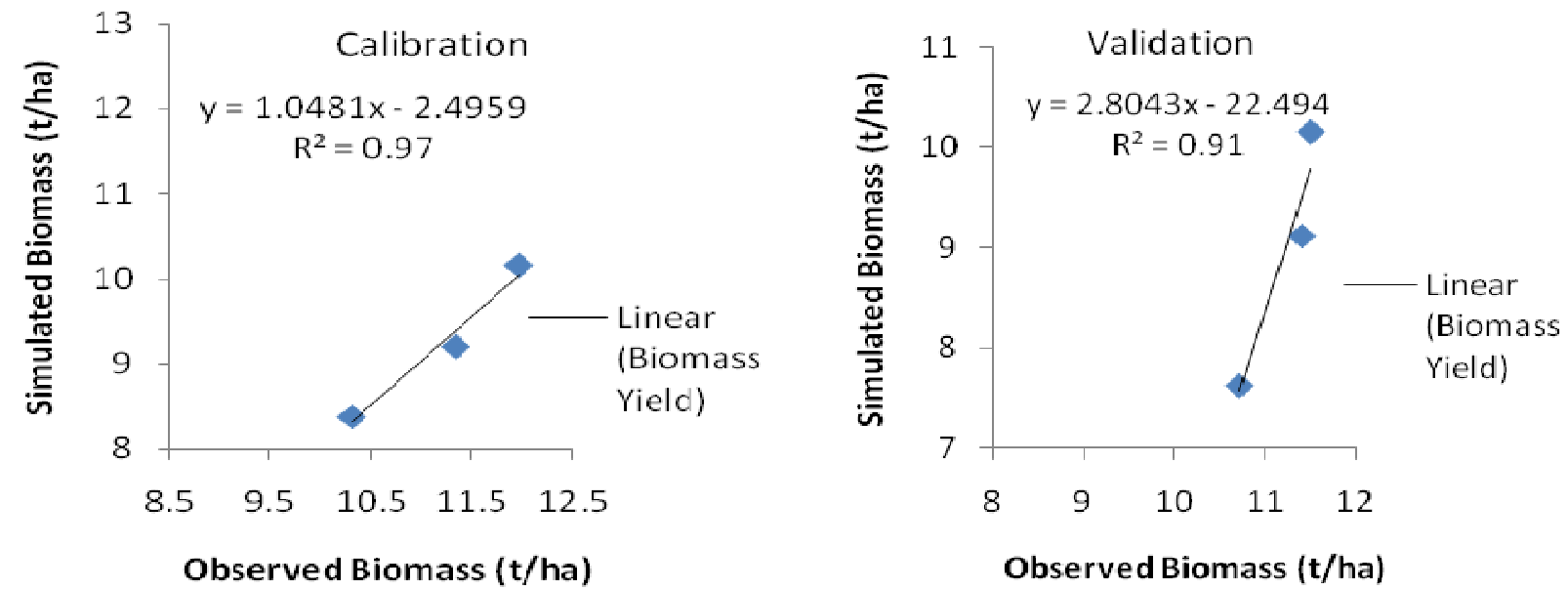

Fig. 5. Model calibration and validation results for biomass yield under three different irrigation regimes during rabi $2011-12$.

Table 1. Climatic parameters during entire crop growing season of 2010-11 and 2011-12.

\begin{tabular}{|c|c|c|c|c|c|c|c|c|}
\hline \multirow{2}{*}{$\begin{array}{l}\text { Weather pa- } \\
\text { rameters } \\
\text { months }\end{array}$} & \multicolumn{2}{|c|}{$\begin{array}{l}\text { Temperature }\left({ }^{0} \mathrm{C}\right) \\
(\mathbf{m a x})\end{array}$} & \multicolumn{2}{|c|}{$\begin{array}{l}\text { Temperature }\left({ }^{0} \mathrm{C}\right) \\
(\mathrm{min})\end{array}$} & \multicolumn{2}{|c|}{ Rainfall (mm) } & \multicolumn{2}{|c|}{ Mean RH (\%) } \\
\hline & $2010-11$ & 2011-12 & $2010-11$ & 2011-12 & 2010-11 & 2011-12 & 2010-11 & 2011-12 \\
\hline December & 21.05 & 22.13 & 5.89 & 5.03 & 0.25 & 0 & 67 & 59.33 \\
\hline January & 18.37 & 18.7 & 5.68 & 5.45 & 0 & 14.8 & 67 & 63.02 \\
\hline February & 23.19 & 22.96 & 9.96 & 7.83 & 37.88 & 0 & 70 & 50.1 \\
\hline March & 29.88 & 30.18 & 13.74 & 13.26 & 0.86 & 0 & 61.5 & 48.67 \\
\hline April & 34.66 & 34.9 & 17.32 & 18.85 & 0 & 6.8 & 44.5 & 45.74 \\
\hline Mean & 25.43 & 25.774 & 10.52 & 10.084 & 38.99 & 21.6 & 62 & 53.372 \\
\hline
\end{tabular}

Table 2. Soil physical and chemical properties of experimental field.

\begin{tabular}{lllllll}
\hline Soil depth $(\mathbf{c m})$ & $\mathbf{B}_{\mathbf{d}}\left(\mathbf{g} / \mathbf{c m}^{\mathbf{3}}\right)$ & $\mathbf{F}_{\mathbf{C}}(\mathbf{w} / \mathbf{w})$ & $\mathbf{P W P}(\mathbf{w} / \mathbf{w})$ & $\mathbf{K s}\left(\mathbf{c m d}^{\mathbf{- 1}}\right)$ & $\mathbf{E C}\left(\mathbf{d s m}^{\mathbf{- 1}}\right)$ & $\mathbf{p H}$ \\
\hline $0-15$ & 1.41 & 21.3 & 9.5 & 24.7 & 0.24 & 7.7 \\
$15-30$ & 1.43 & 22.8 & 10.2 & 26.2 & 0.34 & 8.1 \\
$30-45$ & 1.39 & 24.1 & 13.7 & 18.6 & 0.35 & 8.01 \\
$45-60$ & 1.37 & 24.9 & 14.7 & 19.1 & 0.37 & 8.05 \\
$60-90$ & 1.36 & 26.3 & 15.0 & 19.5 & 0.38 & 8.5 \\
\hline
\end{tabular}

$\mathrm{B}_{\mathrm{d}}$ : Bulk Density, Ks: Saturated Hydraulic conductivity, $\mathrm{F}_{\mathrm{C}}$ : Field Capacity, PWP: Permanent Wilting Point, EC: Electrical Conductivity 
Table 3. Different agronomic practices of the experiments during rabi season of 2010-11 and 2011-12.

\begin{tabular}{lll}
\hline Agronomic practices & $\mathbf{2 0 1 0 - 1 1}$ & $\mathbf{2 0 1 1 - 1 2}$ \\
\hline Sowing date & 25.11 .10 & 02.12 .11 \\
Pre sowing fertilization $\left(\mathrm{kg} \mathrm{ha}^{-1}\right)$ & $\mathrm{P}_{2} \mathrm{O}_{5} ; 60, \mathrm{~K}_{2} \mathrm{O} ; 40$ & $\mathrm{P}_{2} \mathrm{O}_{5} ; 60, \mathrm{~K}_{2} \mathrm{O} ; 40$ \\
Irrigation supplies & 4 & 4 \\
Total water used $(\mathrm{mm})$ & $179,242,306$ & $165,227,289$ \\
$\left(\mathrm{~W}_{1}, \mathrm{~W}_{2}, \mathrm{~W}_{3}\right)$ & & \\
Harvest date & 07.04 .11 & 15.04 .12 \\
Length of growing season & 134 & 136 \\
\hline
\end{tabular}

Table 4. Crop parameters with unit and their specific value used in experiment.

\begin{tabular}{lllll}
\hline Parameters & \multicolumn{3}{c}{ Value } & Unit \\
\cline { 2 - 4 } & FI & $\mathbf{2 5 \%}$ DI & $\mathbf{5 0 \%}$ DI & \\
\hline Base temperature & 0.0 & 0.0 & 0.0 & ${ }^{0} \mathrm{C}$ \\
Upper temperature & 39 & 39 & 39 & ${ }^{0} \mathrm{C}$ \\
Canopy growth coefficient & 14.7 & 14.4 & 14.3 & $\% /$ day \\
Canopy decline coefficient & 11.3 & 14.3 & 15.2 & $\% /$ day \\
Canopy expansion threshold $\left(\mathrm{P}_{\text {upper }}\right)$ & 0.20 & 0.19 & 0.20 & \% of TAW \\
Canopy expansion threshold $\left(\mathrm{P}_{\text {lower }}\right)$ & 0.74 & 0.50 & 0.50 & \% of TAW \\
Canopy expansion shape factor & 3 & 3 & 3 & Unit less \\
Stomatal closure threshold $\left(\mathrm{P}_{\text {upper }}\right)$ & 0.65 & 0.65 & 0.65 & \% TAW \\
Stomatal closure shape factor & 2.5 & 2.5 & 2.5 & Unit less \\
Early canopy senescence threshold $\left(\mathrm{P}_{\text {upper }}\right)$ & 0.70 & 0.70 & 0.70 & $\%$ of TAW \\
Early canopy senescence shape factor & 2.5 & 2.5 & 2.5 & Unit less \\
Maximum basal crop coefficient $\left(\mathrm{K}_{\mathrm{cb}}\right)$ & 1 & 1 & 1 & Unit less \\
Time from sowing to emergence & 6 & 6 & 6 & Days \\
Time from sowing to maximum canopy & 50 & 50 & 50 & Days \\
Time from sowing to senescence & 117 & 117 & 117 & Days \\
Time from sowing to maturity & 133 & 133 & 133 & Days \\
Duration of flowering & 7 & 7 & 7 & Days \\
Time from sowing to maximum root depth & 85 & 85 & 85 & Days \\
\hline
\end{tabular}

FI: Full Irrigation, DI: Deficit Irrigation, TAW: Total Available Water

Table 5. Observed and simulated grain yield ( $\mathrm{t} / \mathrm{ha})$, water productivity $\left(\mathrm{kg} / \mathrm{m}^{3}\right)$ and biomass $(\mathrm{t} / \mathrm{ha})$ of wheat cultivar HD-2894.

\begin{tabular}{|c|c|c|c|c|c|c|c|c|c|c|c|c|}
\hline \multirow{2}{*}{$\begin{array}{c}\text { Irrigation } \\
\text { regimes }\end{array}$} & \multicolumn{6}{|c|}{ Calibration (2010-11) } & \multicolumn{6}{|c|}{ Validation 2011-12 } \\
\hline & \multicolumn{2}{|c|}{ Yield (ton/ha) } & \multicolumn{2}{|c|}{ WP $(\mathrm{kg} / \mathrm{m} 3)$} & \multicolumn{2}{|c|}{ Biomass } & \multicolumn{2}{|c|}{ Yield (ton/ha) } & \multicolumn{2}{|c|}{ WP $(\mathrm{kg} / \mathrm{m} 3)$} & \multicolumn{2}{|c|}{ Biomass(ton/ha) } \\
\hline & Observed & Simulated & Observed & Simulated & Observed & Simulated & Observed & Simulated & Observed & Simulated & Observed & Simulated \\
\hline Full Irrigation & 4.95 & 4.93 & 1.42 & 2.01 & 11.96 & 10.15 & 4.75 & 4.89 & 1.40 & 2.01 & 11.51 & 10.15 \\
\hline $25 \% \mathrm{DI}$ & 4.4 & 4.44 & 1.59 & 1.93 & 11.33 & 9.20 & 4.41 & 4.37 & 1.73 & 1.97 & 11.42 & 9.12 \\
\hline $50 \%$ DI & 4.01 & 4.01 & 1.79 & 1.87 & 10.31 & 8.38 & 3.82 & 3.52 & 2.11 & 1.84 & 10.72 & 7.62 \\
\hline
\end{tabular}

Table 6. Prediction error of yield, water productivity and biomass of wheat during calibration and validation.

\begin{tabular}{|c|c|c|c|c|c|c|}
\hline \multirow[t]{2}{*}{ Irrigation regimes } & \multicolumn{2}{|c|}{ Grain Yield $\mathrm{P}_{\mathrm{e}}( \pm \%)$} & \multicolumn{2}{|l|}{$\mathbf{W P} \mathbf{P}_{\mathrm{e}}( \pm \%)$} & \multicolumn{2}{|c|}{ Biomass $P_{e}( \pm \%)$} \\
\hline & Calibration & Validation & Calibration & Validation & Calibration & Validation \\
\hline Full Irrigation & 0.42 & 2.95 & 41.55 & 43.57 & 15.13 & 11.81 \\
\hline $25 \%(\mathrm{DI})$ & 0.89 & 0.91 & 21.38 & 13.87 & 18.81 & 20.16 \\
\hline $50 \%$ DI & 0.05 & 7.85 & 4.47 & 12.80 & 18.73 & 28.96 \\
\hline
\end{tabular}

DI: Deficit Irrigation

Table7. Model Efficiency (ME) and Mean Absolute Error (MAE) of modeled grain yield, water productivity and biomass yield of wheat during calibration and validation.

\begin{tabular}{|c|c|c|c|c|}
\hline \multirow[t]{2}{*}{ Output } & \multicolumn{2}{|l|}{ ME } & \multicolumn{2}{|l|}{ MAE } \\
\hline & Calibration & Validation & Calibration & Validation \\
\hline Yield & 0.99 & 0.99 & 0.02 & 0.16 \\
\hline WP & -5.85 & -0.99 & 0.34 & 0.37 \\
\hline Biomass & -7.32 & -4.85 & 1.96 & 2.26 \\
\hline
\end{tabular}

ME: Model Efficiency, MAE: Mean Absolute Error 
tion water.

Estimation of crop evapotranspiration: Soil water budget method was used to estimate actual crop evapotranspiration (ETa). The components of water balance equation within the soil profile up to root zone depth were measured using Equation (2)

$\mathrm{ET}_{\mathrm{c}}=\mathrm{P}+\mathrm{IR}+\mathrm{C}_{\mathrm{p}}-\mathrm{D}_{\mathrm{p}}-\mathrm{R}_{\mathrm{o}} \pm \Delta \mathrm{W}$

Where,

$\mathrm{ET}_{\mathrm{c}}$ is crop evapo-transpiration $(\mathrm{mm}), \mathrm{P}$ is precipitation $(\mathrm{mm})$, IR is total irrigation depth $(\mathrm{mm}), \mathrm{C}_{\mathrm{p}}$ is capillary contribution from ground water table to the crop root zone $(\mathrm{mm}), \mathrm{D}_{\mathrm{p}}$ is deep percolation losses $(\mathrm{mm})$, $\mathrm{R}_{\mathrm{o}}$ is runoff $(\mathrm{mm})$ and $\Delta \mathrm{W}$ is the change in soil water content $(\mathrm{mm})$. The basins in the experimental plots were closed by bunds and the water table depth was 4 $\mathrm{m}$ below the ground surface. Therefore, the surface runoff and the vertical upward seepage or the capillary flow to the root zone was assumed negligible in the calculation of ET using Equation 2. Besides this, the drainage below root zone, after a number of soil-water content measurements, was considered to be negligible. So the Equation 2 was reduced to:

$\mathrm{ETc}=\mathrm{P}+\mathrm{IR} \pm \Delta \mathrm{W}$

Input data for the AquaCrop model: Operation of AquaCrop model requires input data consisting of climatic parameters, crop, soil and field and irrigation management data.

Climate data: The climate data required for AquaCrop model are daily rainfall, minimum and maximum air temperature, reference crop evapotranspiration (ETo), and mean annual carbon dioxide concentration $\left(\mathrm{CO}_{2}\right)$. ETo was estimated by ETo calculator using the daily maximum and minimum temperature, wind speed at $2 \mathrm{~m}$ above ground surface and hours of bright sunshine.

Crop data: In AquaCrop, the crop file contained 13 phenological crop growth stages with canopy and root development, evapotranspiration, water, fertility, and temperature stress parameters. The list of crop parameters with unit and their value used in this experiment is presented in Table 4.

Soil parameters: Soil parameters of experiment site required for AquaCrop model as input data are number of soil horizons, soil texture, field capacity (FC), permanent wilting point (PWP), saturated hydraulic conductivity (Ksat), volumetric water content at saturation (sat) and initial soil moisture content and its salinity. The experiment site did not contain any impervious or restrictive soil layer to obstruct the expansion of root growth. The curve number $(\mathrm{CN})$ of the site was used to estimate surface runoff from rainfall that occurred during the experiment.

Irrigation and field management parameters: Irrigation and field management during the experiment are two important components considered in the AquaCrop model. In full irrigation treatment, water was applied up to field capacity level when soil moisture in the root zone approached $50 \%$ of total available water (TAW). In the deficit irrigation treatments (i.e. 75 and $50 \%$ of full irrigation or 25 and $50 \%$ deficit irrigation, respectively), depths of irrigation in different plots were reduced to 75 and $50 \%$ of the full irrigation. The field management components were the fertility level and height of bunds to eliminate surface runoff. In this study there was no limit of fertility and $0.1 \mathrm{~m}$ bund height was considered. The details of agronomic practices during the crop growing season have been listed in Table 3.

Calibration of AquaCrop model: Calibration of the AquaCrop model was accomplished by using the observed values from the field experiment of wheat during 2010-11 rabi season as model input and then simulating the model to predict the output viz. the grain and biomass yield and water productivity (WP). Subsequently, the predicted output values of these parameters were compared with the observed wheat grain yield, biomass and water productivity of the experimental plot. The difference between the model predicted and observed values of experiment was minimized by using trial and error approach in which one specific input variable was chosen as the reference variable at a time and adjusting only those parameters that were known to influence the reference variable the most. The procedure is repeated several times to arrive at the closest match between the model simulated and observed value of the experiment for each irrigation regimes.

Validation of AquaCrop model: Calibrated AquaCrop model was validated using the weather and the irrigation depth information during the wheat growing period of rabi 2011-12 to predict the grain yield, biomass and water productivity of wheat. Further, the AquaCrop model simulated values were compared with the observed values of the experiment and the model validation performance statistics were estimated.

Model evaluation criterion: The goodness of fit between the simulated and observed values was verified by using the prediction error statistics. The prediction error $\left(\mathrm{P}_{\mathrm{e}}\right)$ and mean absolute error (MAE) was used as the error statistics to evaluate both the calibration and validation results of the model. The model efficiency (ME) (Nash and Sutcliffe, 1970) shows efficiency of the model in simulation of the parameters and coefficient of determination $\left(\mathrm{R}^{2}\right)$ determines the discrepancy between simulated and observed values. These error statistics were used to evaluate the predictive power of the model. In this study, the model output in terms of prediction for grain and biomass yield besides water productivity during harvest was considered for evaluation of the model. The model evaluation parameters are given by:

$$
\mathrm{P}_{\mathrm{e}}=\frac{\left(\mathrm{S}_{\mathrm{i}}-\mathbf{O}_{\mathrm{i}}\right)}{0 \mathrm{i}} \times 100
$$




$$
\begin{aligned}
\text { MAE }= & \frac{\sum\left|S_{i-} O_{i}\right|}{n} \\
& \frac{\sum_{i=1}^{\mathrm{N}}(\mathrm{Oi}-\mathrm{Si})^{2}}{\sum_{\mathrm{i}=1}^{\mathrm{N}}(\mathrm{Oi}-\overline{\mathrm{O}})^{2}}
\end{aligned}
$$

Where, $\mathrm{S}_{\mathrm{i}}$ and $\mathrm{O}_{\mathrm{i}}$ are predicted and actual (observed) data, Ōis mean value of $\mathrm{O}_{i}$ and $\mathrm{N}$ is the number of observations. Model efficiency (ME) and $\mathrm{R}^{2}$ approaching one and Pe and MAE close to zero are indicators for better model performance.

\section{RESULTS AND DISCUSSION}

AquaCrop model calibration and validation results: Calibration of the AquaCrop model was accomplished by using the observed values from the field experiment during rabi 2010-11 as model input parameters and then operating the model to obtain the simulated output in terms of grain yield, biomass and water productivity. The calibrated model parameters are presented in Table 4.The model predicted outputs were compared with the observed grain yield, water productivity and biomass under different irrigation regimes. Observed and model simulated grain yield, water productivity and biomass yield during calibration and validation are presented in Table 5. It was observed from Table 5 that the grain yield varied from 4 to 4.95 ton/ha during the model calibration and 3.82 to 4.75 ton/ha during the validation of the AquaCrop model under different irrigation regimes. The model prediction error was estimated and presented in Table 6 . It was observed from Table 6 that the grain yield prediction when compared with validation data set of rabi 2011-12 and calibrated using the rabi 2010-11 data set resulted in absolute prediction error of $2.95 \%, 0.91 \%$ and $7.85 \%$ for full, $25 \%$ deficit and $50 \%$ deficit irrigation levels, respectively. Water productivity varied from 1.84 to $2 \mathrm{~kg} / \mathrm{m}^{3}$ during calibration and validation process. Water productivity under full irrigation $\left(\mathrm{W}_{3}\right)$ treatment was the lowest whereas that for 50\% DI the WP was the highest for both the calibrated and validated model simulations. It was observed from Table 6 that the calibrated model while simulating the water productivity resulted in an absolute prediction error of $41.55 \%, 21.38 \%$ and $4.47 \%$ for full, $25 \%$ deficit and $50 \%$ deficit irrigation regimes, respectively. The model validation results indicated that for full, $25 \%$ and $50 \%$ deficit irrigation levels the prediction error varied from 12 to $44 \%$. However, the model performed well in predicting water productivity for $50 \%$ deficit irrigation treatment when compared with other irrigation treatments. The reason for poor prediction of water productivity by AquaCrop model can be attributed to the difference in the estimation procedure of water productivity used in the model simulation process and as estimated using the experiment data. Similar results were also reported by Abedinpour et al. (2012), Iqbal et al. (2014),
Kumar et al. (2014) and Kumar et al. (2015) in which the model performed better for prediction of grain and biomass yield as compared to the water productivity. Above ground biomass yield varied from 10.31 to 11.96 t/ha and 10.42 to 11.51 t/ha during rabi $2010-11$ and 2011-12 growing seasons, respectively. The full irrigation treatment produced highest above ground biomass compared to other irrigation regimes. It was observed that the model predicted biomass yield by validated AquaCrop model was with prediction error of $11.81 \%, 20.16 \%$ and $28.96 \%$ for full, $25 \%$ DI and $50 \%$ DI, respectively (Table 6). The model efficiency (ME) and mean absolute error (MAE) of model prediction for grain yield, water productivity and biomass yield is presented in Table 7. It was observed from Table 7 that the ME is 0.99 for both calibration and validation for grain yield, varied from -5.85 and -0.99 for WP during calibration and validation, respectively. Also, the comparison of model simulated and observed biomass yield resulted in ME of -7.35 and -43.85 for calibrated and validated model, respectively. It was also observed that the model was validated for grain and biomass yield under all irrigation regimes with prediction error statistics $0.16<\mathrm{MAE}<2.26 \mathrm{t} \mathrm{ha}^{-1}$ (Table 7). Moreover, the model simulated and observed grain and biomass yield for both calibration and validation processes is shown in Figs 4 and 5, respectively. It was observed that the $\mathrm{R}^{2}$ for grain yield was 0.99 for both calibration and validation (Fig. 4), whereas for biomass yield the $\mathrm{R}^{2}$ was 0.97 and 0.91 during model calibration and validation processes, respectively (Fig. 5).

Similarly, the model prediction error for water productivity was 13.9 and $12.8 \%$ under $25 \%$ and $50 \%$ deficit irrigation regimes, respectively. However, the model prediction error was $43.6 \%$ for full irrigation treatment. The difference in AquaCrop model simulated water productivity and the water productivity estimated using the experiment data as mentioned above was due to the fact that the AquaCrop model estimates the water productivity as a ratio of grain yield to the total crop evapotranspiration during the growing period. Whereas, in the field experiment, the sum of irrigation water supplied to the field using the soil moisture deficit criterion and the effective rainfall during the growing season accounts for the total water used and the water productivity is estimated by dividing the grain yield with the total water use. The AquaCrop model considered the total crop evapotranspiration during the growing period of wheat to be the total water used for crop growth and subsequently, the grain yield was divided with the total crop evapotranspiration for estimating water productivity. The total crop evapotranspiration during the crop growing period was less than the sum of irrigation water applied and the effective rainfall during the growing season. Therefore, water productivity was observed to be more as simulated by AquaCrop model when compared with the 
experiment data, which is basically due to the difference in the computation of total water as estimated in AquaCrop model and analyzing the data acquired from the field experiment. Therefore, the comparison of water productivity between the AquaCrop model simulated and observed values indicated higher prediction error. Nonetheless, it was observed that the model performed well for prediction of grain and biomass yield but failed to predict the water productivity for all irrigation regimes when compared with the observed data generated from the field experiment.

\section{Conclusion}

It was observed that the AquaCrop model could simulate the grain and biomass yield of wheat with prediction error ranging from 0.91 to $7.85 \%$ and 11.81 to $28.96 \%$, respectively under three irrigation regimes. Experiment generated data of rabi 2010-11 and 201112 and AquaCrop model simulated results revealed that wheat grain yield and above ground biomass were significantly affected under full and deficit irrigation regimes. However, the AquaCrop model prediction for grain yield of wheat was better under full irrigation and $25 \%$ deficit irrigation with prediction error of 2.95 and $0.91 \%$ as compared to the $50 \%$ deficit irrigation treatment with prediction error of $7.85 \%$. Similarly, for biomass yield, the model performed well with prediction accuracy of $11.81 \%$ under full irrigation as compared to deficit irrigation regimes. However, the model failed to predict the water productivity in line with the experimental results. Nonetheless. it can be recommended from this study that the AquaCrop model,which requires less model input data in comparison to other crop models can be used for prediction of wheat grain and biomass yield with acceptable accuracy under variable irrigation regimes in a semi-arid environment as that of the experiment region.

\section{ACKNOWLEDGEMENT}

Authors wish to acknowledge the National Agricultural Science Fund (NASF) funding agency (Project code DSS-2025) of Indian Council of Agricultural Research (ICAR) for undertaking the modelling studies using the FAO AquaCrop model.

\section{REFERENCES}

Abedinpour, M., Sarangi, A., Rajput, TBS., Singh, M., Pathak, H., Ahmad, T. (2012). Performance evaluation of AquaCrop model for maize crop in a semi-arid environment. Agric. Water Manage. 110:55-66.

Andarzian, B., Bannyan, M., Steduto, P., Mazraeh, H., Barati, M.E., Rhnama, A. (2011). Validation and testing of the AquaCrop model under full and deficit irrigated wheat production in Iran, Agric. Water Manage., 100: 1-8.

Iqbal, M.A., Shen, Y., Stricevic, R., Pei, H., Sun, H., Amiri, E., Penas, A., Rio, S. del., (2014). Evaluation of the FAO AquaCrop model for winter wheat on the North China Plain under deficit irrigation from field experiment to regional yield simulation. Agric. Water Manage. 135:61-72.

Kumar, P., Sarangi, A., Singh, D.K., Parihar, S.S. (2014). Evaluation of AquaCrop model in predicting wheat yield and water productivity under irrigated saline regimes, Irrig. Drain., 63 (4): 474-487.

Kumar, P., Sarangi, A., Singh, D.K., Parihar, S.S., Sahoo, R.N. (2015). Simulation of salt dynamics in the root zone and yield of wheat crop under irrigated saline regimes using SWAP model, Agric. Water Manage., 148: 72-83.

Mkhabela, M.S., and Bullock, P.R. (2012). Performance of the FAO AquaCrop model for wheat grain yield and soil moisture, Agric. Water Manage., 110: 16-24.

Nash, J.E., Sutcliffe, J.V. (1970). River flow forecasting through conceptual models. I. A discussion of principles. J. Hydro., 10: 282-290.

Salemi, H., Soom, M.A.M., Lee, T.S., Mousavi, S.Y., Ganji, A. and KamilYusoff, M. (2011). Application of AquaCrop model in deficit irrigation management of winter wheat in arid region. Afr. J. Agric. Res., 610: 2204-2215.

Singh, A., Saha, S., Mondal, S. (2013) Modelling irrigated wheat production using the FAO AquaCrop model in West Bengal, India for Sustainable Agriculture. Irrig. Drain., 62: 50-56.

Steduto, P., Hsiao, T.C., Raes, D. and Fereres, E. (2009). AquaCrop-the FAO Crop Model to Simulate Yield Response to Water: I. Concepts and Underlying Principles. Agron. J., 101: 426-437.

Xiangxiang, W., Quanjiu, W., Jun, F., Qiuping, F. (2013). Evaluation of the AquaCrop model for simulating the impact of waterdeficits and different irrigation regimes on the biomass and yield of winter wheat grown on China's Loess Plateau, Agric. Water Manage., 129: 95104. 